Finally, we believe it may be easier to injure the long thoracic nerve and the thoracodorsal nerve through the posterior approach, affecting muscle development and thoracic symmetry. Thus we do not advocate using the posterior approach.

Lit Ying-long, $M D$

Department of Cardiovascular Surgery Fu Wai Cardiovascular Institute and Cardiovascular Diseases Hospital

Chinese Academy of Medical Sciences Peking Union Medical College A 167, Beilishi Rd, Xicheng District Beijing. 100037 People's Republic of China

12/8/97044

\section{Anterior approach to the superior sulcus tumors: The transmanubrial osteomuscular sparing approach} To the Editor:

We read with great interest the brief communication by Onuki and associates ${ }^{1}$ concerning a new modification of the anterior approach to superior sulcus tumors. The surgical treatment of cervicothoracic tumors has long been a challenge for thoracic surgeons, and the search of the "ideal" approach has influenced the development of different proposals. All the same, the treatment of apical chest tumors presents two series of problems: (1) dissection of the neoplasm from the cervicothoracic structures and (2) pulmonary hilar and lymph node dissection.

Concerning the first problem, three main approaches are available: the hemi-clamshell and Masaoka techniques, the anterior transcervical approach, and finally the transmanubrial osteomuscular sparing approach (TMA). The advantages and limits of each type have been widely reported and dis- cussed elsewhere, ${ }^{2-4}$ and each new proposal should be compared with these documented approaches.

Theoretically, the ideal approach for the treatment of lung cancer should reach the following oncologic and functional targets: (1) wide exposure of the thoracic inlet and outlet, allowing the control of the vessels arising from the subclavian artery as well as the control of the axillary and innominate arteries in case of subclavian artery en bloc resection. (2) the possibility to dissect the brachial plexus, (3) the complete resection of cervical lymph nodes, (4) the posterior resection or disarticulation of the first and second ribs when infiltrated, (5) the possibility to preserve the muscular insertions of the cervicothoracic muscles to improve cervical and chest wall stability, and finally (6) the maintenance of the integrity of the clavicle with its articulation with the manubrium and its muscular insertions (sternocleidomastoid and major pectoral muscles).

Onuki and colleagues ${ }^{1}$ again propose that the clavicle be sectioned, a procedure that has repeatedly been demonstrated to be unnecessary. ${ }^{2-4}$ In fact, sacrificing the clavicle contributes to shoulder instability, weakness, and deformity, mainly when a large chest wall resection or vertebrectomy is associated. In any case, even when reinstalled, fixation of the sternoclavicle articulation can lead to shoulder immobility or, more frequently, to painful pseudoarthrosis. Besides, Onuki has clearly confirmed in his series that fixing the two stumps of the clavicle with wires of plates is frequently insufficient and associated with late fracture, mainly in patients who underwent preoperative radiotherapy. The results of this series are paradigmatic; $60 \%$ (3/5) of the patients had late insufficient fixation or fracture of the reinstalled clavicle. ${ }^{1}$ In conclusion, even reimplantation of the clavicle can be associated with important disadvantages for the patient. This is

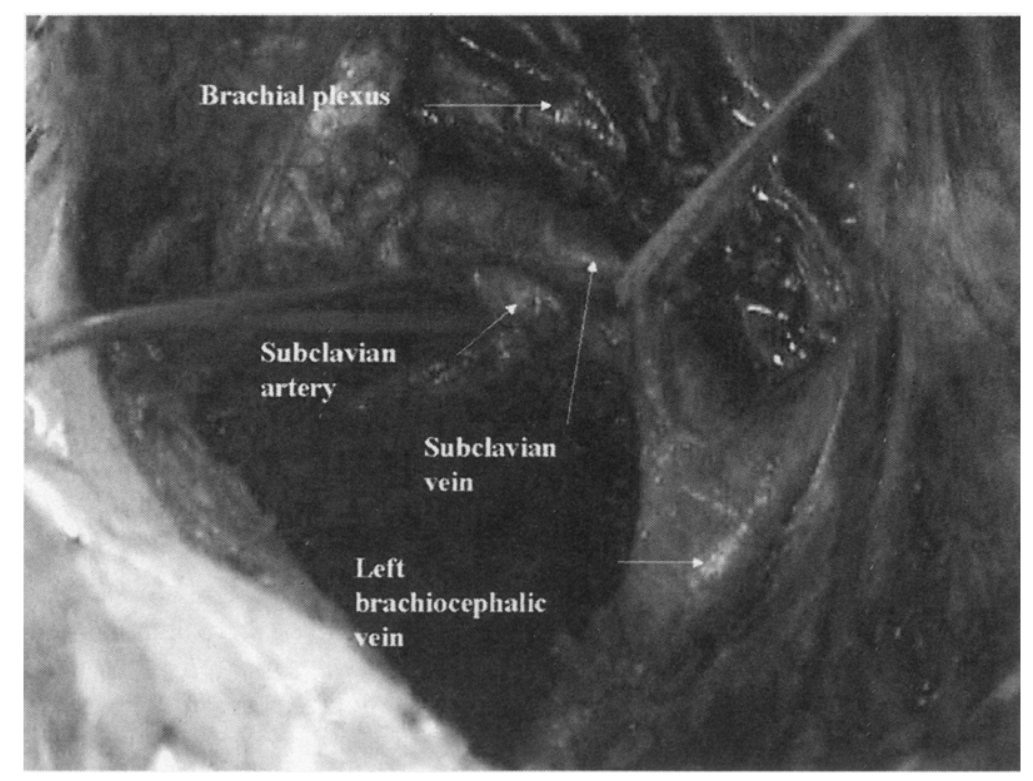

Fig 1. Operative photograph. This patient underwent the TMA for an apical non-small cell lung carcinoma invading the anterior part of the first and second ribs. 


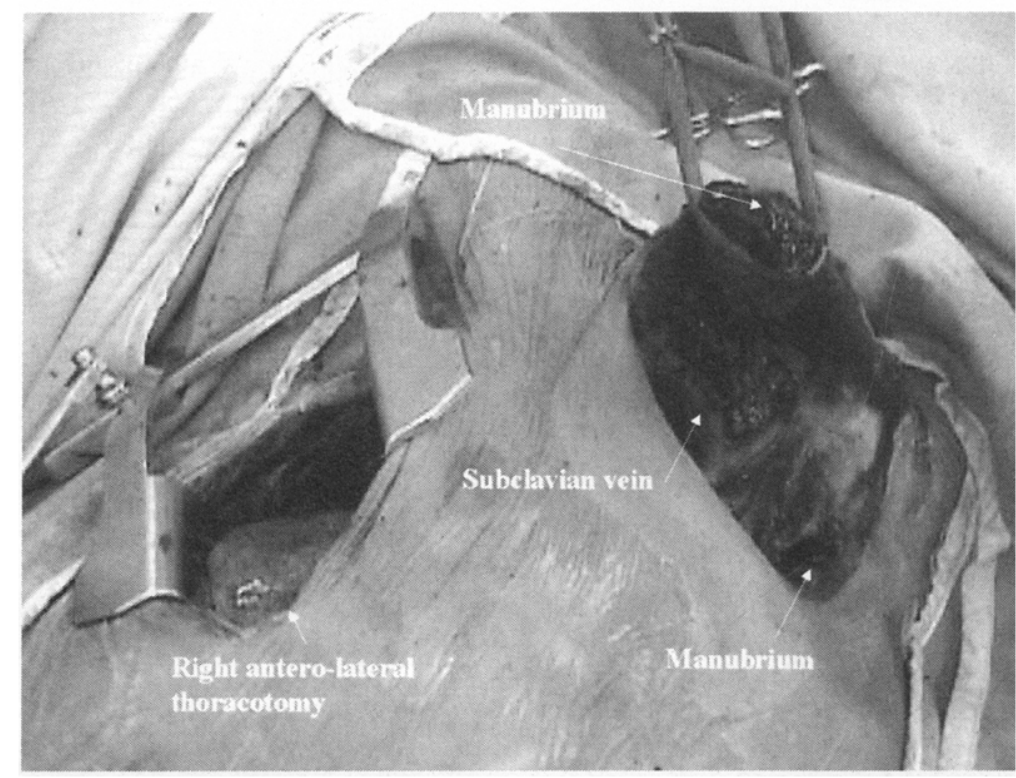

Fig 2. Operative photograph of the same patient shown in Fig 1. An upper right lobectomy with radical lymph node dissection was performed through the anterior muscle sparing thoracotomy. The analysis of the specimen showed a pT3 pN0 non-small cell lung carcinoma.

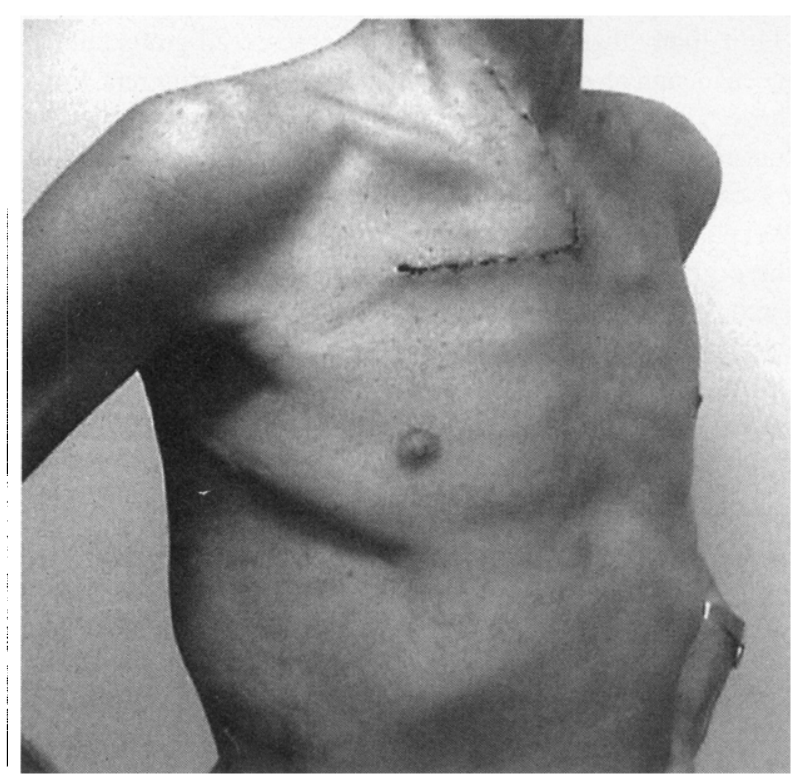

Fig 3. Postoperative photograph at discharge. Note the integrity of the clavicle.

clearly one of the reasons for the increased popularity of the TMA. $^{3.4}$ With this approach the operative cervicothoracic field is wide (Fig 1), permitting subclavian artery resection ${ }^{5}$ but respecting osteoarticular and muscular components.

The second problem concerning lung resection and hilar lymph nodes dissection can be solved by a further posterolat- eral thoracotomy, a median sternotomy, or by resecting the third and fourth cartilages during the TMA. The possibility to modulate the thoracic approach according to the pulmonary resection required and the surgeon's preference is another important advantage of the TMA.

For apical non-small cell lung carcinoma without vertebral invasion, we have recently been combining TMA plus anterolateral muscle sparing thoracotomy, which does not necessitate changing the patient's position on the operating table. This approach is excellent in terms of lung resection and radical lymph node dissection (Figs 1 to 3). At present our experience includes 13 cases of TMA performed for different cervicothoracic tumors ( 8 cases of apical non-small cell lung carcinoma). In this series, early and late functional and aesthetic results of the cervicothoracic approach were excellent.

Even though the choice among the different approaches still depends on surgeon preference, in recent years TMA has been progressively adopted by several European thoracic surgeons, mainly because it provides wider exposure combined with less invasiveness for the patient.

Lorenzo Spaggiari, $M D, P h D$

Ugo Pastorino, $M D$

Department of Thoracic Surgery

European Institute of Oncology

Via Ripamonti 435

Milan 20141, Italy

\section{REFERENCES}

1 Onukı T. Murasugı M. Mae M. Sone Y, Keı J. Nitta S. Modıfication of anterior approach to superior sulcus tumor. $\mathbf{J}$ Thorac Cardiovasc Surg 1998:116 663-4 
2. Korst RJ, Burt ME. Cervicothoracic tumors: results of resection by the "hemi-clamshell" approach. J Thorac Cardiovasc Surg 1998;115:286-95.

3. Grunenwald D, Spaggiari L. Transmanubrial osteomuscular sparing approach for apical chest tumor. Ann Thorac Surg 1997; 63:563-6

4. Grunenwald D, Spaggiari L, Girard P, Baldeyrou P. Transmanubrial approach to the thoracic inlet. $\mathrm{J}$ Thorac Cardiovasc Surg 1997;113:958-9.

5. Spaggıarı L, Pastorino U. Subclavian artery involvement by apical chest tumors: a specific indication for the transmanubrial approach [letter]. J Thorac Cardiovasc Surg 1999;117:627.

$12 / 8 / 96850$

\section{Reply to the Editor:}

We also recognize the importance of maintaining the integrity of the clavicle with its articulation with the manubrium and its muscular insertions. Spaggiari and Pastorino concluded that our method does not maintain the integrity of the clavicle because there was insufficient fixation in 3 of our 5 cases. However, they were the early cases. Our problem in the early period lay in the method of fixing the sectioned clavicle. However, besides gaining some technical experience, we solved the problem by fixing the clavicle with a new material, slightly thicker titanium plates. No problems at all have been encountered in the 2 most recent cases. The patients are even bowling with the arm on the side of the operation.

Section of the manubrium is also possible with our method. When performed, it would probably be done by the ordinary thoracic approach. Spaggiari and Pastorino have stated that our method and their method are completely different procedures. Although we also considered the procedure from a totally different viewpoint, when we evaluated the matter thoroughly, it seemed reasonable to conclude that our method is also a TMA.

The main portion of our report says that "sectioning the clavicle in the TMA makes it possible to enlarge the field of vision and at the same time maintain clavicle integrity." An approach to a fairly large portion of the great vessels in the thoracocervical area may very well be possible without sectioning the clavicle if the procedure is performed carefully. However, the field of vision obtained by sectioning the clavicle makes it possible to visualize the great vessels in the thoracocervical area frontally in a way that cannot be compared with the exposure available when the clavicle is not sectioned. The field of vision must be enlarged if the operation is to be performed safely.

Takamasa Onuki, MD First Department of Surgery Tokyo Women's Medical University 8.1 Kawada-chou Shinjuku-ku Tokyo 162-8666, Japan

12/8/96849

\section{Homograft valve failure in children \\ To the Editor:}

We read with interest the article by Rajani, Mee, and Ratliff. ${ }^{1}$ Their finding of a lymphocytic infiltrate associated with rapid failure of cryopreserved homografts in infants lends support to the hypothesis of an immunologic injury being at least partially responsible for this failure. This concurs with our own clinical ${ }^{2}$ and laboratory ${ }^{3}$ findings but is not supported by others. ${ }^{4}$

Rajani, Mee, and Ratliff end their article with speculation about the possible use of tissue matching and immunosuppression in these patients. Although we believe that there is evidence for an immunologic component to this accelerated failure, we would caution against the empiric use of immunosuppression in these children without further controlled studies. In a small pilot study we transplanted cryopreserved aortic valve grafts into 21 outbred rats as previously described ${ }^{3}$ and randomly assigned 11 to receive oral cyclosporine (10 $\mathrm{mg} / \mathrm{kg}$ per day) (INN: ciclosporin) for 56 days while the remaining 10 received a placebo. The striking finding of this study was that only 3 of the 11 grafts in the cyclosporinetreated group remained patent at 8 weeks whereas 8 of 10 in the placebo group were patent $(P=.03$, Fisher's exact test). The patent cyclosporine grafts did have less medial necrosis and perivascular inflammation than control grafts. The cause of this high occlusion rate in the cyclosporine-treated group is unknown but may be due to a direct toxic effect of cyclosporine on the endothelium of these small grafts. ${ }^{5}$ Whether the same effect would occur in larger grafts is unknown.

It is likely that these avascular cryopreserved grafts fail by mechanisms of rejection that are substantially different from those affecting vascularized whole organs. Thus directly transferring immunosuppressive regimens used successfully for cardiac or renal transplantation may not be appropriate. We postulate that there is an immune-mediated attack on these grafts that damages their structural elements, making them more susceptible to early degeneration. Much more work is required to determine if this indeed is the case and to determine how best to minimize this response. We do not believe that sufficient data are yet available to recommend immunosuppression in children requiring homograft valves.

David B. Ross, $M D$ Gillian R. Hamilton, $B A$ James R. Wright, Jr, $M D, P h D$ Timothy D. G. Lee, PhD Division of Cardiovascular Surgery IWK Grace Hospital for Children PO Box 3070

Halifax, Nova Scotia, Canada B3J 3 G9

\section{REFERENCES}

1. Rajani B, Mee RB, Ratliff NB. Evidence for rejection of homograft cardiac valves in infants. J Thorac Cardiovasc Surg 1998; 115:111-7.

2. Baskett RJ, Ross DB, Nanton MA, Murphy DA. Factors in the early falure of cryopreserved homograft pulmonary valves in children: Preserved immunogenicity? J Thorac Cardiovasc Surg 1996;112:1170-9.

3. Moustapha A, Ross DB, Bittira B, et al. Aortic valve grafts in the rat: Evidence for rejection. J Thorac Cardiovasc Surg 1997:114: 891-902. 